\title{
Medico-Social and Psychological Aspects of Cardiovascular Diseases
}

\author{
Saida Alirzaevna Magomedova* and Angela Sergeevna Damadaeva
}

Dagestan State University, Building 43-A, Gadzhiyev Street, Mahachkala City, Republic of Dagestan, Russian Federation

*Corresponding author: Magomedova SA, Dagestan State University, Building 43-A, Gadzhiyev Street, Mahachkala City, Republic of Dagestan, Russian Federation; Email: msaika@yandex.ru

Received: Jun 8, 2016; Accepted: Jul 21, 2016; Published: Aug 27, 2016

Copyright: ( 2016 Magomedova et al. This is an open-access article distributed under the terms of the Creative Commons Attribution License, which permits unrestricted use, distribution, and reproduction in any medium, provided the original author and source are credited.

\section{Abstract}

The article analyzes the research of foreign and domestic researchers in the field of psychological measures of prevention, treatment, and rehabilitation of patients with heart disease. We considered psychosocial risk factors and protective factors in patients with cardiovascular disease and present the results of our analysis of the personal characteristics of patients with arterial hypertension and ischemic heart disease, dedicated targets for the development of methods of psychological correction of patients with these diseases as well as recommendations for psychological assistance in cardiorehabilitation, which will give an opportunity to increase the effectiveness of preventive and therapeutic interventions.

Keywords: Cardiovascular disease; Psychocardiology; Depression; Myocardial infarction; Coronary heart disease; Hypertension; Psychological help

\section{Introduction}

Even in presence of the indisputable successes of modern medical science and practice, there is a general anxiety among the population of Russia about the causes of increasing incidences of cancer, cardiovascular diseases (CVD), tuberculosis, diabetes, and tendency to "rejuvenation" and the chronicity of the course. Thus, the main share (over $50 \%$ ) of mortality is accounted by CVD [1].

CVD is represented by a set of psychosomatic diseases, and a significant contributor to its development is stress. These diseases still remain insufficiently studied in terms of individual and typological characteristics of people that are most susceptible to the formation of CVD and in defining of psychological mechanisms, because this knowledge can provide access to specific methods of psychological intervention for prevention of the disease and rehabilitation of patients and, in particular, will help to uncover the motive identity of these patients, especially their psychological maladaptation in the system of "personality disease."

In modern life and in modern medicine there is increasing significance of disease prevention and health consciousness. The principles of European declaration and the European plan of action on mental health care include changing strategies of assistance from therapeutic to preventive, in particular regarding the prevention of diseases of the circulatory system.

More and more hospitals are interested in hiring clinical psychologists for comprehensive treatment and rehabilitation of patients. Ten years ago in the hospitals of USA, clinical psychologists found the most rapid growth [2], which contributed to the rapid development of psychocardiology.

Psychocardiology is not a new discipline but rather an attempt to understand the contribution of psychological measures of prevention, treatment, and rehabilitation of patients with heart disease [3]. From this point of view, the well-being of cardiac patients depends on a holistic interdisciplinary approach in the assessment of psychological and cardiovascular problems. It is important that knowledge and skills obtained from training in clinical psychology are adapted to the needs of cardiac patients of different age, sex, and with various disorders.

By definition of the American Psychological Association [4], clinical psychology integrates science, theory, and practice to understand, predict, and relieve maladjustment, disability, and discomfort as well as to facilitate adaptation, fitness, and personal development. Clinical psychology focuses on intellectual, emotional, biological, psychological, social, and behavioral aspects of human functioning throughout a life, in different cultures and at all socioeconomic levels, where psychodiagnostics and psychotherapy are central to the practical activities of psychologists.

In recent years, cardiologists have been paying more attention to psychosocial risk factors and their association with somatic disorders that appear in studies of arterial hypertension and ischemic heart disease focusing on psychocardiology [5]. Unfortunately, in our country today medical, social, and psychological aspects of CVD are not adequately represented, which are important for social satisfaction of patients.

Historically, the first works in the field of psychocardiology most often were associated with studies of traits of personality and coronary heart disease. In the late 1950s cardiologists M. Friedman and R. Rosenman described a complex sequence of behavior and effects of the personality as "behavioral pattern type A" [6]. And even though there was no unanimous decision about the association of type-A personality with heart disease, these studies have become an important starting point, as they demonstrated possible specific personality traits that can negatively affect heart health.

Further studies were conducted focused on identifying behavioral factors of addictive behavior, which contributed to the development of cognitive-behavioral programs aimed at modification of risk factors [7]. Subsequently, more and more works have reported the relationship between disorders of the cardiovascular system and psychopathology, focusing on heightened anxiety level, clinical manifestations of depression, excessive workload, distress, and social isolation [8]. The relationship between psychosocial risk factors and the prevalence and course of heart diseases is reliable and relevant. In particular, in 
a significant number of patients, a psychological distress was observed after the diagnosis of cardiac performances [9].

Let's consider some psychosocial risk factors in more detail.

It is known that social isolation, low level of social protection, and limited social relationships have a negative impact on the human health in general and on the development of CVD in particular. So, different studies have shown that single and lonely patients with CVD had a threefold increase in mortality compared with those who had a partner or were married [10]. Another study has proved that the single life leads to recurrence of cardiac pathology, particularly in the initial stages of their development [11].

In a study of patients with myocardial infarction (MI) in anamnesis, it was revealed that the increase in mortality during the 6-month postinfarction period was not associated with MI but with such risk factors as smoking and hypertension [12]. The study identified a direct link between social factors and the percentage of patients who had MI and died during the 6-month period of rehabilitation. These studies suggest that the lack of social assistance, social contacts, and, in particular, social isolation give rise to social tensions and lead to certain behavioral reactions and changes on a psychological level that over time can lead to the development or destabilization of CVD.

In populational studies where were used figures of a different social strata, it was showed statistically that social activity contributes to the improvement of health status [13]

According to the results of another study [14], as protective factors against coronary heart disease (CHD) in patients who belonged to the group of a social comfort, were recognized:

- the emotional support or loyalty of close friends or family members

- a real, practical help of relatives and friends;

- good advices and assistance in assessing and overcoming difficulties and problems; and

- belonging or feeling the need to belong to a group of people with common values and interests.

The last three functions are usually provided by a big social group, whereas emotional support can be found in the family and in a circle of closefriends.

Another important aspect of social support and comfort is a close emotional relationship, providing comfort, trust, love, and increasing feeling of self-sufficiency, which is a positive measure in preventing MI. The absence of such relationships increases the risk for MI.

A depressive mood is one of the mechanisms that determine the risk of CVD. Depression is associated with an increased risk of myocardial and other cardiovascular diseases; patients with depression after MI have five times higher mortality risk compared with patients without depression [15].

In addition, all North American and European studies show that depression in cardiac patients has an independent effect on increased risk of mortality. In clinical practice it is important to predict and take appropriate measures to prevent worsening of patients' mood.

\section{Methods}

As we have just said, the goal of this work was to study the personality characteristics of patients with hypertension and coronary artery disease to determine the targets of psychotherapeutic work.
To achieve this goal 138 people with their informed consent were investigated (on the basis of the State Budgetary Institution of the Republic of Dagestan, "The republican cardiologic dispensary of the Ministry of Health of the Republic of Dagestan," and SBI of the Republic of Dagestan “Polyclinic №7”, Makhachkala) and were formed into three groups.

In the first main group were included 57 patients suffering from hypertension of the first or the second stage. In the second main group, 51 patients with CHD. The comparative group consisted of 20 practically healthypersons.

In all threegroupspatientsof 41-50 and 51-60 yearsofagedominated (the first main group: 32.7 and $31.3 \%$, respectively; the second main group: 34.7 and $32 \%$, respectively; and the comparative group: -29 and $27.5 \%$, respectively). According to the gender distribution in the firs and second main groups the percentages of women were, respectively, 62.6 and $64.7 \%$ and those of men were 37.4 and $35.3 \%$, respectively. In the comparative group, women were $65.5 \%$ and men were $34.5 \%$.

The survey was conducted on the principle of random selection, when all units of a general totality have an equal opportunity of being sampled. The surveyed contingent was homogeneous for all baselines, which allows considering that the results of the study reflect the representative population.

The procedure of investigation of personal status included the use of the following psychodiagnostic methods:

(a) questionnaire of the dominant character traits by $\mathrm{K}$. Leongard and G. Shmishek, designed to diagnose the type of accentuation of character of a person;

(b) the individual typological questionnaire (ITQ).

\section{Results}

The distribution of accentuation types inherent in the examined contingent was as follows:

Among the surveyed patients of the first main group (arterial hypertension, $\mathrm{AH})$ the following types of character accentuations were dominant: emotive (69.52 $64.2 \%$ ), anxiety (49.38 $64.8 \%$ ), Demonstrative $(37.4665 .1 \%), \quad$ getting stuck $\quad(59.85 \quad 6$ 4.8\%), hyperthymic (29.33 6 4.7\%).

Among the surveyed patients of the second main group (patients with CHD), the distribution of accentuation was somewhat different So, the typical values for this group were: alarming (71.74 $64.5 \%)$, emotive (68.22 $65.0 \%$ ), getting stuck (55.87 $65.1 \%$ ) and dysthymic (57.33 $64.8 \%)$ types of accentuations.

In the surveyed patients of a comparative group (85.00 6 4.0\%) no types of accentuation were detected.

Thus, according to the obtained data, $68 \%$ of patients with hypertension and $63 \%$ with coronary artery disease have the emotive type of accentuation. They are characterized by emotionality, sensitivity, anxiety, talkativeness, apprehension, and deep reactions in the field of fine feelings. These people are impressionable; they rarely come into conflict; they are carrying their images in themselves, do not throw them out. They are characterized by a heightened sense of duty and diligence.

For patients (AH, 53\% and CHD, 76\%) with alarming accentuation, it is peculiar: a lack of confidence, a heightened sense of duty, responsibility, and high moral and ethical requirements. They then to 
disguise their sense of inferiority with a self-assertion through those activities where they can develop their full potential. Anxious persons have fear and anxiety.

Distinctive features of patients with hypertension were demonstrativeness and hyperthymity. They are characterized by demonstrative behavior, by the ability to displacement, significant mobility, sociability, expressiveness of gestures, facial expressions, excessive independence, excessive self-regard.

In patients with CHD, a dysthymic type of accentuation was observed. This was manifested in depressed mood, slowness, weak willpower pessimism, low level of sociability and self-esteem, tendency to fixate on negative experiences, and therefore a distrust and wariness toward others, sensitivity to hurts and grief, suspicion, and tendency to an affective response.

Thus, in hypertensive patients extroversion and communication skills were combined with emotive signs: emotions, sensuality, anxiety, impressionability, "close to tears," the desire to avoid conflicts in the background of demonstrativeness and of hyperthymity.

In turn, in CHD patients with introversion and a high level of a personal anxiety there were symptoms of emotional instability: increased emotionality, sensitivity, susceptibility, vulnerability, indecision, lack of self-confidence, excessive concern about his health and future in the background of being trapped and dysthymia.

Psychological characteristics of a personality were measured using the ITQ.

Surveyed patients from the first main group (AG) were characterized by the presence of anxiety, sensitivity, conformity, and lability; they were communicative and extroversion in combination with poor health and mood, and a lack of spontaneity. This indicated the presence of mental stress, a low level of energy potential, a weakness of "personal core values," and confusion.

The level of social activity (a desire for communication) in this case was inadequate relative to the existing physiological condition, as a communicative activity while one is feeling unwell, and nervousity had a more debilitating effect. So, in this case, there was a frustration of physical and social activity of a person, which contributed to the increasing of mental stress and the emergence and deepening of the psychopathological condition. It is important to note that patients with hypertension differ from inadequate perception of reality, as evidenced by the increased rates on a scale of "correction" (in other words, they tend to see the world and themselves as they want). Therefore, their expectations tend to be frustrated by reality, have become an additional source of psychic tension and neurotic experiences. In addition, these patients revealed a higher level of sensitivity and lability (in comparison with patients with CHD) with high demands of themselves. Among individuals with hypertension the internal conflict of a personality has a basis in the presence of incompatible trends: a high motivation for action and the absence of psychological qualities and mental forces to implement them. Also, there is a very deep concentration of patients on their own problems, as evidenced by a moderate level of individualism, introversion, rigidity, and conformity.

Surveyed patients from the second main group (CHD) were characterized by the presence of anxiety, sensitivity, lability, introversion, conformity, and a rigid fixation on the traumatic memories. Thus, this type of a person, fixated on his or her own negative experiences had communication problems, which worsened the psychological perspective.
From the personal characteristics of the individuals in the second group, the deep concentration by the patients on themselves, on their problems should be noted, as evidenced by the excessive level of individualism and rigidity. They are characterized by tendency to compensatory exalted self-affirmation in a communication, going beyond the problems associated with their own disease, as evidenced by the high indicators of anxiety scales and sensitivity combined with a moderate level of lability, extroversion, and compromise.

The basis for the emergence of psychological problems in this surveyed group was identified: personal instability, emotional weakness, inability for constructive cognitive processing of life experiences, and inadequate assessment of themselves, of people around, and of the situation.

Thus, the comparative analysis of individual-typological qualities of the personality by the method of ITQ in patients of different groups was characterized by the dominance of the following personality tendencies: high level of anxiety, sensitivity, lability, conformability, and a low level of spontaneity at a high tendency to rigidity.

\section{Discussion}

The analysis of individual psychological characteristics of persons suffering from diseases of the circulatory system helped to differentiate them and to identify those which are peculiar to patients with hypertension and coronary artery disease (the difference is statistically significant: $p \square 0.01$ )

So, patients with hypertension have the following characteristics:

- a combination of emotive, disturbing, demonstrative, getting stuck, hyperthymic types of accentuation to a high degree of severity;

- prevalence of communicative problems, lability, extroversion, anxiety, sensitivity, and conformability with poor health and mood, lack of spontaneity (which indicates the presence of mental stress);

- weakness of "personal core values," confusion.

Patients suffering from ischemic heart disease are characterized by the following features:

- a combination of anxiety, emotive, getting stuck, dysthymical types of accentuation to a high degree of severity;

- a combination of anxiety, sensitivity, lability, introversion, conformity, and a rigid fixation on traumatic memories.

Thus, patients with hypertension and coronary artery disease both have general and individual psychological features that contribute to the development of diseases of the cardiovascular system, and have different features, which become the psychological component of the pathogenesis of specific diseases.

In our opinion, the obtained data may become the basis for the development of the system of psychological care for patients with hypertension and coronary artery disease, which indicates the necessity of bringing the doctor-psychologist (clinical psychologist) into a multidisciplinary team that deals with patients with cardiovascular diseases at the stage of cardiac rehabilitation.

Cardiac rehabilitation is a multicomponent and coordinated intervention aimed at optimizing physical, psychological, and social functioning and reducing morbidity and mortality of patients with cardiovascular diseases $[16,17]$. 
After shifting the focus from direct pathology to the identity of the patient, the psychologist is becoming an important member of the multidisciplinary team. He can help cardiologists in the following fields [18]:

- maintaining a patient during the hospitalization, when it enters into a therapeutic alliance, aid in the modification of lifestyle, and the working out of traumatic events related to feeling a "victim" after a heart attack;

- personalization of therapy, which will improve the dialogue between a doctor and a patient;

- if necessary, providing a differential diagnosis.

In Italian guidelines for psychological care in cardiorehabilitation [19] are reserved five phases of communication that characterize the interaction between cardiac patient and a psychologist:

1. Selection. Patients have the right to request and receive psychological counseling.

2. Entry. Reflects the first contact between the patient and the psychologist.

3. Assessment. The aim is to identify psychological problems, needs, resources, and a collection of all data necessary for appropriate intervention. In this phase it is important to focus on nonadaptive behaviors and habits of the patient in the pathopsychological aspects.

4. Intervention. Psychological support in the rehabilitation of the patient and a family. Activities include the following tasks:

- the recognition and expression of emotional experiences related to illness;

- identification and implementation of mechanisms that help to control risk factors and modify lifestyle;

- restore a satisfactory quality of life.

These psychological interventions contain group and individual counseling and psychotherapy (mainly cognitivebehavioral), learning strategies, stress management, and selfhelp activities.

5. Remote support. In this phase the patient's satisfaction with the quality of life and the need for further medical support is determined.

\section{Conclusion}

Currently there is an extensive set of interrelated psychosocial factors and CVD risk, and therefore there is a need for a thorough study. This will allow diverse preventive measures that will enhance the effect of cardiac treatment. Such events not only help to reduce the risk of recurrent episodes of acute forms of CVD, but also improve the quality of life of patients. Today there is a significant need in the development of differentiated methods of secondary prevention and rehabilitation of patients with cardiovascular diseases. While the psychological and social methods are very promising, there is also a need for the development of effective models to study the interaction between different psychosocial factors and the establishment of scientific basis for developing preventive psychological interventions. In any way, psychologists can help to analyze the effectiveness of medical interventions to clinicians and to compare the quality of life and the psychoemotional status of patients before and after a surgical treatment, to develop a comprehensive system of medical and psychological care for patients with CVD from the stage of primary diagnosis of CVD and a further remote cardiopathology support.

\section{References}

1. Askhabova LM (2010) A course of lectures on public health and healthcare. Educational-methodical manual for students of FPC faculty of medical schools approved by the EMA, Ministry of Health of the Russian Federation, Makhachkala, 2010, p. 404.

2. Benjamin LT, Jr (2005) A history of clinical psychology as a profession in America (and a glimpse at its future). Annu Rev Clin Psychol 1: 1-30.

3. Molinari E (2006) Clincial Psychology and Heart Disease. Milan: Springer- Verlag Italia, pp. 5-18.

4. American Psychological Association (Division 12): Society of Clinical Psychology.

5. Callus E (2010) Elements of psychocardiology in the psychosocial handling of adults with congenital heart disease. Front Psychol 1: 34

6. Friedman M (1959) Association of specific overt behavior pattern with blood and cardiovascular findings; blood cholesterol level, blood clotting time, incidence of arcus senilis, and clinical coronary artery disease. J Am Med Assoc 169: 1286-1296.

7. Bennett SJ, Cordes DK, Westmoreland G, Castro R, Donnelly E (2000) Self- care strategies for symptoms management in patients with chronic heart failure. Nurs Res 49: 139-145.

8. Kovacs AH, Silversides C, Saidi A, Sears SF (2006) The role of the psychologist in adult congenital heart disease. Cardiol Clin 24: 607-618.

9. Rozanski A, Blumenthal JA, Davidson KW, Saab PG, Kubzansky L (2005) The epidemiology, pathophysiology, and management of psychosocial risk factors in cardiac practice: the emerging field of behavioral cardiology. J Am Coll Cardiol 45(5): 637-651.

10. Fitzgerald TE (2000) Health risk reduction and functional restoration following coronary revascularisation: a prospective investigation using dynamic stage typology clustering. Int J Rehab Health 5: 99-116.

11. Sebregts EH (2000) Risk factor modification through nonpharmacological interventions in patients with coronary heart disease. J Psychosom Res 48: 425-441.

12. Fleet R, Lawie K, Beitman BD (2000) Is panic disorder associated with coronary artery disease? A critical review of the literature. J Psychosom Res 48: 347-356.

13. Kaasen A (2010) Acute maternal social dysfunction, health perception and psychological distress after ultrasonographic detection of a fetal structural anomaly. Int J Obstet Gynecol 117: 1127-1138.

14. Helfricht S, Latal B, Fischer JE, Tomaske M, Landolt MA (2008) Surgery related posttraumatic stress disorder in parents of children undergoing cardiopulmonary bypass surgery: a prospective cohort study. Pediatr Crit Care Med 9: 217-223.

15. Kaasen A, Helbig A, Malt UF, Naes T, Skari H, et al. (2013) Paternal psychological response after ultrasonographic detection of structural fetal anomalies with a comparison to maternal response: a cohort study. BMC Pregnancy Childbirth 13: 147.

16. Majnemer A, Limperopoulos C, Shevell M, Rosenblatt B, Rohlicek C, et al. (2006) Long-term neuromotor outcome at school entry of infants with congenital heart defects requiring open-heart surgery. J Pediatr 148: 72 77 .

17. Magomedova S, Damadaeva A (2014) Application of physical education in the rehabilitation of patients with cardiovascular disease. Biol Med 6.

18. Leon AS, Franklin BA, Costa F, Balady GJ, Berra KA, et al. (2005) Cardiac rehabilitation and secondary prevention of coronary heart disease. Circulation 111: 369-376.

19. Sommaruga M, Tramarin R, Angelino E, Bettinardi O, Cauteruccio $M A$, et al. (2003) Guidelines on psychological intervention in cardiac rehabilitation- methodological process. Monaldi Arch Chest Dis 60: 40 44. 